\title{
Development of protective immunity to Salmonella, a mucosal pathogen with a systemic agenda
}

\author{
AJ Griffin ${ }^{1}$ and SJ McSorley ${ }^{1}$
}

\begin{abstract}
Salmonella infections can cause a range of intestinal and systemic diseases in human and animal hosts. Although some Salmonella serovars initiate a localized intestinal inflammatory response, others use the intestine as a portal of entry to initiate a systemic infection. Considerable progress has been made in understanding bacterial invasion and dissemination strategies, as well as the nature of the Salmonella-specific immune response to oral infection. Innate and adaptive immunity are rapidly initiated after oral infection, but these effector responses can also be hindered by bacterial evasion strategies. Furthermore, although Salmonella resides within intramacrophage phagosomes, recent studies have highlighted a surprising collaboration of CD4 Th1, Th17, and B-cell responses in mediating resistance to Salmonella infection.
\end{abstract}

\section{INTRODUCTION}

Salmonella infections cause intestinal and systemic diseases in human and animal hosts and are an important public health priority worldwide. ${ }^{1-3}$ Greater understanding of the immune response to Salmonella is required to provide a solid foundation for the development of new and improved vaccines against these infections. Furthermore, the complex interplay between the host immune response and bacterial virulence factors during Salmonella infection provides an ideal model to understand the biological intersection of two competing genomes. Indeed, there is a long history of microbiologists and immunologists examining the murine model of Salmonella infection as it allows examination of these important issues while also allowing a natural oral route of infection. ${ }^{4-10}$ This review will focus on our current understanding of bacterial dissemination and host immunity after oral infection with Salmonella, with a particular emphasis on the most recent findings obtained from the murine model.

\section{DISEASE CAUSED BY SALMONELLA INFECTION}

Salmonella is a Gram-negative facultative intracellular pathogen that causes a spectrum of clinical diseases depending on the infecting bacterial serovar and the underlying host susceptibility. ${ }^{11}$ Salmonella infections fall broadly into three categories, namely (i) localized intestinal infection (gastroenteritis), (ii) systemic infection of an otherwise healthy host (typhoid), and (iii) systemic infection of a selectively susceptible or an immune-compromised host (non-typhoidal Salmonellosis).

\section{Salmonella gastroenteritis}

Large Salmonella outbreaks associated with the ingestion of contaminated food products are now a common occurrence. ${ }^{12-14}$ In the United States, $~ 50 \%$ of food-borne infections are caused by bacteria, and approximately $30-50 \%$ of these can be attributed to Salmonella serovars. ${ }^{15,16}$ Patients suffer from a localized intestinal infection that includes fever, diarrhea, and cramping, but most healthy individuals recover without treatment within 4-7 days. ${ }^{9}$ In contrast, patients with a weakened immune status or underlying health conditions can develop a fatal infection during these outbreaks, and Salmonella remains the leading cause of food-borne fatalities in the United States. ${ }^{1,15}$ Importantly, these intestinal infections can be initiated by any 1 of $~ 2,000$ different Salmonella serovars that infect humans and various animal reservoirs.

\section{Typhoid fever}

Salmonella enterica serovars Typhi and Paratyphi are the causative agents of typhoid fever, a disease characterized by fever and hepatosplenomegaly, with subsequent intestinal hemorrhage or perforation also possible. ${ }^{11}$ These clinically indistinguishable infections are responsible for an estimated 27.1 million cases and 217,000 deaths every year in developing nations. ${ }^{17}$ Unlike the Salmonella serovars causing gastroenteritis, these particular

\footnotetext{
${ }^{1}$ Division of Gastroenterology, Hepatology and Nutrition, Department of Medicine, Center for Infectious Diseases and Microbiology Translational Research, McGuire Translational Research Facility, University of Minnesota Medical School, Minneapolis, Minnesota, USA. Correspondence: SJ McSorley (mcsor002@umn.edu) 
Salmonella serovars are highly restricted to the human host. Thus, preventative measures such as improving sanitation, food hygiene, and clean drinking water can be effective in disrupting human-to-human transmission. ${ }^{18}$ However, the substantial improvements in societal infrastructure that would be required to prevent typhoid transmission are cost prohibitive and are unlikely to have a significant impact on reducing typhoid incidence in the near future. ${ }^{19}$ In contrast, the generation of safe and effective typhoid vaccines that could be used routinely and safely in endemic areas would be more likely to have a significant impact on typhoid. ${ }^{2}$ There are currently two licensed typhoid vaccines, each with moderate efficacy against this disease (3-year cumulative efficacy of 50-55\%); however, neither of these vaccines is widely used in endemic areas. ${ }^{20}$ The improvement or replacement of these existing vaccines will likely require greater understanding of host immunity to Salmonella infection.

There are also several unusual features of typhoid that suggest the development of incomplete or partial immunity in naturally exposed individuals. First, a chronic carrier condition occurs in a proportion of typhoid patients or exposed asymptomatic individuals. ${ }^{8,11}$ This carrier state is caused by persistent gall bladder infection and can result in long-term bacterial shedding in stools with few clinical signs of infection. ${ }^{8,11}$ Second, there is some evidence that individuals living in endemic areas suffer from repeated bouts of typhoid, a finding that suggests a relatively poor natural development of acquired immunity. ${ }^{11}$ Third, relapse of the primary typhoid is believed to occur in $5-15 \%$ of patients after apparent resolution of disease. ${ }^{11,21}$ These clinical relapses occur in untreated typhoid patients but are also commonly observed after antibiotic treatment of primary infection. $^{22-25}$ Each of these clinical issues highlights the perplexing ability of Salmonella to persist for extremely long periods of time in an otherwise immune-competent host and/or the failure of acquired immune responses to effectively resolve primary or secondary infection. Understanding the immunological basis of these issues would likely provide a clearer understanding of protective immunity in the infected host and may also be key to the improvement in vaccine development against typhoid. Fortunately, animal models are now available that allow a detailed study of persistent bacterial shedding, ${ }^{26,27}$ antibioticmediated relapsing disease, ${ }^{28}$ and the perplexing failure of the host to develop robust immunity after primary infection. ${ }^{29}$ Therefore, it is likely that bacterial virulence factors and immunological parameters associated with these clinical issues can be elucidated in the future.

\section{Disseminated NTS}

As noted above, non-typhoidal serovars of Salmonella normally cause gastroenteritis but can also cause fatal infections when host immunity is compromised..$^{30}$ These non-typhoidal serovars can also cause disseminated infections that lack gastrointestinal symptoms and may be transmitted by human-to-human contact rather than through an animal reservoir. ${ }^{31-33}$ These unusual features are likely to be caused by an ongoing host adaptation of NTS strains in endemic areas. ${ }^{34}$ There is currently no vaccine against NTS, and greater understanding of host immunity to disseminated infection is required. Although this disease is relatively rare in developed nations, disseminated NTS infections are increasingly associated with HIV (human immunodeficiency virus)-infected individuals in Asia and Africa. ${ }^{30,35-37}$ In addition, a small cohort of patients with primary interleukin (IL)-12 and IL-23 signaling deficiencies display markedly increased susceptibility to NTS, ${ }^{38}$ and these cytokines are important for the differentiation of Th1 and Th17 cells. Disseminated NTS has also been reported to occur in HIV-negative young children and the fatality rate of these patients is high. ${ }^{31,32}$ Evidence from these young patients suggests that Salmonellaspecific antibody contributes to the development of protective immunity against NTS. ${ }^{39}$ Taken together, these findings suggest a requirement for $\mathrm{CD} 4 \mathrm{Th} 1$ and Th17 cells, plus an essential role for antibody in the resolution of NTS. Indeed, a similar conclusion can also be drawn from mouse studies that will be discussed in more detail below.

\section{MOUSE MODELS OF SALMONELLA INFECTION}

Microbiologists and immunologists have examined immunity to Salmonella in mice because this model is easy to work with in the laboratory and reproduces many important aspects of human Salmonellosis. ${ }^{40}$ As might be expected, this animal model has some limitations, most notably that Salmonella-infected mice do not develop diarrhea, although this is also a variable symptom in human systemic Salmonellosis. Therefore, studies of the bacterial and host processes leading to Salmonella gastroenteritis are best examined using larger animal models. ${ }^{9}$ However, pretreatment of mice with antibiotics allows for rapid development of intestinal colitis in response to Salmonella infection, and this model is now widely used to examine the inflammatory responses accompanying intestinal bacterial infection. ${ }^{41}$ This approach to examining gastrointestinal inflammation has its own limitations as it requires the unphysiological elimination of the microbiota and uses strains of Salmonella that may also cause systemic disease. However, it represents a useful murine model to understand gastrointestinal inflammation in response to oral infection. The murine model of Salmonella colitis has been reviewed in detail, ${ }^{42}$ and will therefore not be discussed in any depth in this current review.

Another perceived limitation of the mouse model is that systemic infection can be initiated after infection with the Salmonella serovars Typhimurium or Enteritidis, although neither of these serovars causes human typhoid. However, it should be noted that both these serovars can cause systemic Salmonellosis in susceptible humans. As noted above, the serovars that cause typhoid are exquisitely adapted to humans and therefore cannot be examined in mice after oral infection. ${ }^{43}$ This discordance in serovar susceptibility between mouse and humans causes an inevitable disconnection between clinicians working on immunity to human typhoid and basic scientists studying immunity to oral Salmonella infection in mice. This is unfortunate, as a deeper understanding of immunity to systemic Salmonellosis in the mouse model is likely to have implications for our understanding of systemic human Salmonellosis, whether due to NTS or typhoid serovars. However, it is currently 
unclear whether disseminated Salmonellosis in the murine model can serve as a useful preclinical model of typhoid or represents something more akin to NTS in immune-compromised individuals. A decent argument can be made for the latter interpretation as highly susceptible mouse strains that succumb to Salmonella express a susceptible allele of the solute carrier family 11a member 1 (Slc11a1) gene (formerly known as Nramp-1), allowing uncontrolled bacterial growth. ${ }^{8}$ However, it should also be noted that innately resistant mice expressing the resistant allele of Slc11a1 also develop disseminated persistent infections with Salmonella. ${ }^{26}$ Perhaps a greater understanding of antigen targeting by the adaptive immune response during human typhoid, NTS, and murine infection will have the potential to resolve whether and how these infections are related and may be helpful in validating or excluding murine infection as a relevant model for important preclinical vaccine studies.

\section{ORAL SALMONELLA INFECTION ANDTHE ESTABLISHMENT OF SYSTEMIC INFECTION}

Although immunity to Salmonella in mice is often studied after intraperitoneal, intravenous, or subcutaneous infection, in most cases, there is no clear justification for using these challenge routes. Indeed, one of the clear advantages of the mouse model is that Salmonella can be administered orally and intestinal mucosa penetration will occur by natural expression of bacterial virulence factors. ${ }^{44,45}$ In some laboratories, orally infected mice are pretreated with sodium bicarbonate to neutralize stomach $\mathrm{pH}$, or may also be fasted for a short period, before delivery of Salmonella by gavage. ${ }^{46}$ Although these pretreatments are not absolutely essential, they serve to reduce mouse-mouse variability in this model and are therefore experimentally useful. Arguably, the most natural method of Salmonella delivery is to simply add virulent organisms to mouse drinking water. Indeed, our laboratory has examined this methodology and have found that mice are reliably infected using this approach, and that the rate of infection and dissemination is very similar to mice administered bacteria by gavage inoculation (Figure 1).

\section{PPs are a portal of entry for Salmonella}

Upon ingestion of Salmonella by the host, bacteria travel from the stomach to the small intestine where they can be transported across the intestinal epithelium. The primary site of Salmonella infection occurs at specialized microfold, or $\mathrm{M}$ cells, which are interspersed among the enterocytes covering the follicle-associated epithelium (FAE) of the Peyer's patch (PP) ${ }^{47}$ (Figure 2). Salmonella are considered to preferentially invade PPs in the distal ileum, but in practice, all intestinal PPs will harbor bacteria after moderate-to-high-dose infection. Early studies found that Salmonella were associated with PPs of orally infected mice within 3-6h of infection ${ }^{4,48}$ and this has been confirmed by more recent temporal studies. ${ }^{49,50}$

Salmonella express a type-III secretion system encoded by Salmonella Pathogenicity Island 1 (SPI-1), which is required for M-cell invasion. ${ }^{51}$ The SPI-1 gene products form a needle-like complex on the bacterial surface that allows injection of effector proteins into the epithelial cell cytosol and initiates pathogen uptake. Characteristic membrane ruffling of $\mathrm{M}$ cells occurs after attachment of Salmonella to glycoprotein 2 in a process mediated by the Ipf fimbrial operon and SPI-1. ${ }^{52-54}$ Salmonella penetration initiates M-cell destruction, thus disrupting the mucosal barrier and also allowing additional entry of bacteria through neighboring enterocytes. ${ }^{47}$ This process is extremely efficient, with $\mathrm{M}$-cell penetration detected within $30 \mathrm{~min}$, and $\mathrm{M}$-cell destruction observed $\sim 60$ min after infection. ${ }^{47}$ After gaining access to the PP through the FAE, Salmonella encounter various phagocyte populations in the underlying subepithelial dome. The subepithelial dome contains dendritic cell (DC) subsets and macrophage populations, each of which can phagocytose Salmonella and then undergo apoptosis induced by the bacteria through a caspase-1-dependent mechanism. ${ }^{55}$ In macrophages, this process is known as pyroptosis, ${ }^{56}$ and is mediated by a large, supramolecular complex termed "pyroptosome." 57 This mode of cell death may be advantageous for bacterial entry, as dissemination to systemic tissues was found to occur more rapidly in wild-type mice than in caspase-1-deficient mice. ${ }^{58}$

\section{M cell-mediated entry outside PPs}

Although M cells are concentrated in PPs, they are also found in other intestinal locations and can therefore mediate Salmonella infection of non-PP intestinal tissues (Figure 2). The most likely non-PP entry route is through bacterial invasion of solitary intestinal lymphoid tissues (SILTs), which are heterogeneous intestinal lymphoid aggregates found in mice and humans that contain certain features of PPs, including the presence of an FAE containing M cells. ${ }^{59,60}$ As might be expected for a structure containing M cells, these SILTs are targeted for entry by intestinal Salmonella in much the same manner as described above for PPs. ${ }^{61}$ Two days after oral Salmonella infection, bacteria were detected by histology in $40 \%$ SILTs of BALB/c mice and in $17 \%$ SILTs of C57BL/6 mice, likely reflecting the greater number of large SILTs in BALB/c mice. ${ }^{61,62}$ Given the fact that there are $>1,000$ SILT structures in the intestine, ${ }^{61}$ it seems very likely that this alternative pathway contributes significantly to overall bacterial uptake outside the PP. Evidence also suggests that SILTs can be important in humans, as both PPs and SILTs displayed inflammation in a study of typhoid patients. ${ }^{63}$ It has been also reported that intravillus $M$ cells, which are sparsely located along the intestinal tract, may serve as a portal of entry for invasive Salmonella ${ }^{64}$ (Figure 2). Indeed, this seems to be the primary route of Salmonella entry in mice that lack organized lymphoid tissues, ${ }^{64}$ although the importance of these $M$ cells in normal mice is currently unclear.

\section{Salmonella infection of the intestinal lamina propria by direct sampling}

Although the entry routes described above involve Salmonella interactions with M cells, the possibility that Salmonella can invade the host by an alternative route that does not involve $\mathrm{M}$ cells has also been discussed in some detail. ${ }^{65,66}$ One interesting possibility is that a population of phagocytes in the lamina propria can capture bacteria directly from luminal contents, thus allowing bacterial entry. ${ }^{66}$ Crucially, this route does not involve 


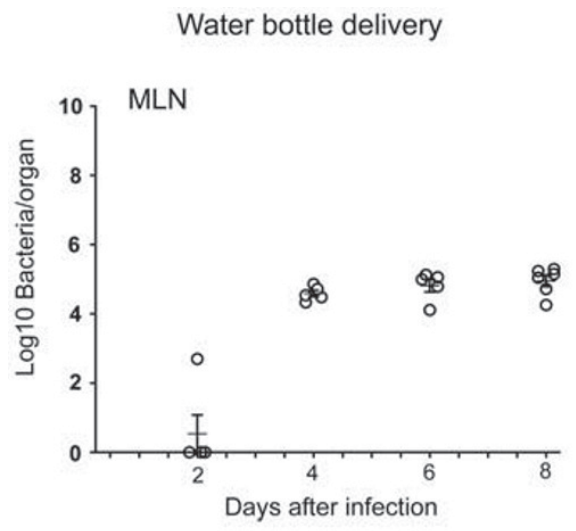

Gavage needle delivery
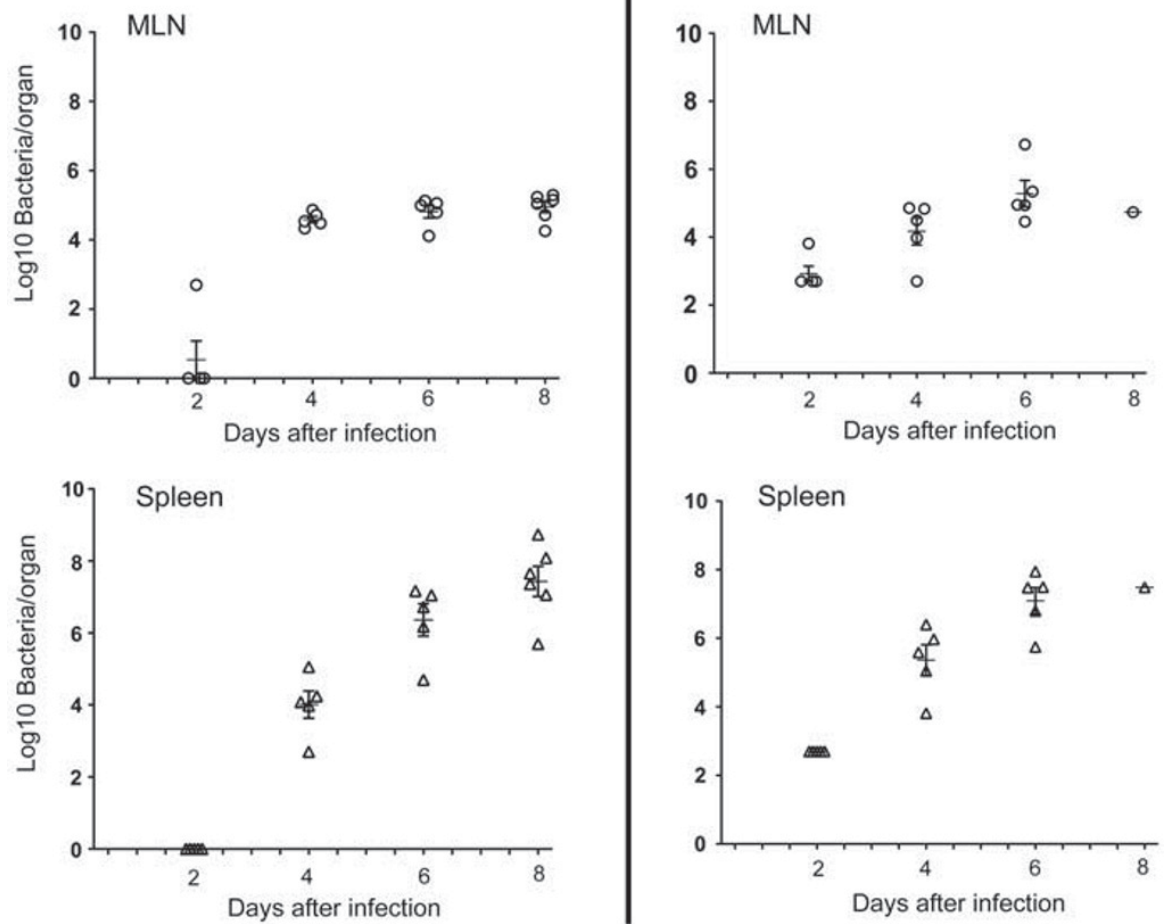

Figure 1 Comparison of Salmonella infection after gavage inoculation or water bottle administration. Groups of C57BL/6 mice were orally infected with $5 \times 10^{7} \mathrm{C}$.f.u. of virulent Salmonella typhimurium (SL1344) by gavage needle, whereas other mice were supplied with drinking water contaminated with SL1344 $\left(1 \times 10^{7}\right.$ c.f.u. $\left.\mathrm{ml}^{-1}\right)$. Organs were harvested at the indicated time points after infection, and bacterial loads were determined by plating organ homogenates on MacConkey's agar. Data show individual mice and mean bacterial load \pm s.d. per time point. c.f.u., colony-forming unit; MLN, mesenteric lymph node.

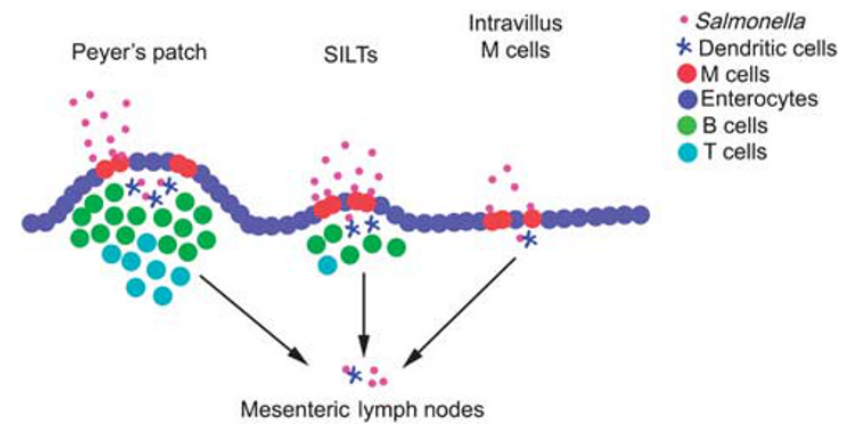

Figure 2 M cell-mediated entry of Salmonella in the small intestine. Salmonella use SPI-1 gene products to induce uptake and destruction of M cells localized over Peyer's patches, solitary isolated lymphoid tissues (SILTs), or scattered throughout the small intestine. The relative importance of these pathways to Salmonella uptake is likely to be Peyer's patches, followed by SILTs, with intravillus M cells having a minor role. After entering the underlying tissue, Salmonella are engulfed by phagocytes, including dendritic cells, which can transport bacteria to the draining mesenteric lymph nodes through the afferent lymphatics. SPI-1, Salmonella Pathogenicity Island 1.

M cell-mediated uptake and is most commonly studied using bacteria that lack SPI-1 genes. Although these cells have often been referred to as DCs, this is by no means clear, ${ }^{67-69}$ and they will therefore be referred to as lamina propria phagocytes in this review. Although this pathway of entry has now become a popular alternative to our conventional understanding of Salmonella entry through M cells, the physiological relevance of this pathway to systemic Salmonellosis remains undefined.

Although the evidence for a non-M-cell pathway is compelling, it derives from a large number of microbiological and immunological investigations that are difficult to reconcile together in a single coherent model. Recent interest was stimulated by an important study demonstrating that Salmonella strains lacking SPI- 1 and the fimbrial $l p f C$ gene retained the ability to infect mice in a CD18-dependent manner, and that these bacteria were detected in the blood within $15 \mathrm{~min}$ of oral inoculation. ${ }^{70}$ Indeed, previous studies had reported the presence of Salmonella in the blood within 2-3 min of oral infection, and surprisingly, this mode of entry was found to be permissive for bacterial serovars that do not normally infect mice. ${ }^{71}$ Given the extremely rapid nature of this dissemination to the blood and the lack of serovar specificity, there remains some concern that bacteria enter the blood stream of the host through abrasions caused during gavage. When using a bacterial imaging system, we detected several instances of Salmonella infection of cervical lymph nodes that we attribute to entry through the mucosal abrasions that occur during gavage. ${ }^{28}$ Although this is a relatively infrequent occurrence and unlikely to explain the findings described above, it does serve to highlight the ability of Salmonella to enter the murine host through unconventional and potentially unphysiological routes. A more recent study has found that bacterial expression of the SPI- 2 type-III secretion 
system effector protein $\mathrm{SrfH}$ was required for very early dissemination of Salmonella to the blood and spleen. ${ }^{72}$ This finding is important and supports the idea that extremely rapid entry through an alternative pathway involves an active and physiological biological process. Therefore, it is vitally important that this pathway be examined in more detail from a microbiological perspective, especially with respect to the bacterial virulence factors required for entry.

The microbiological studies mentioned above are often loosely connected to a series of immunological observations that have examined the capture of luminal bacteria by cells in the lamina propria. However, whether these two processes are in any way connected still remains to be determined. In particular, the extremely rapid kinetics of bacterial entry reported in the studies mentioned above are difficult to reconcile with the time frame required for cell-mediated lamina propria entry and trafficking out of the intestine. In vitro studies initially demonstrated that DCs are able to capture bacteria from the apical surface of epithelial cells by extending processes between the tight junctions of a monolayer. ${ }^{73}$ Subsequently, a similar process was directly visualized in vivo when CX3CR1-expressing phagocytes in the lamina propria were detected extending transepithelial dendrites into the intestinal lumen, and the number of these dendrites increased in the terminal ileum after Salmonella infection. ${ }^{74,75}$ Taken together, these studies suggested an alternative entry model, whereby Salmonella might commonly access the intestinal lamina propria by cell sampling, and in support of this idea, large numbers of bacteria were detected within the lamina propria. ${ }^{74}$ However, Salmonella are not normally recoverable in large numbers from the lamina propria unless the bacterial flora are first depleted before infection., ${ }^{4,41,61}$ Furthermore, the formation of transepithelial dendrites has been found to be dispensable for the uptake of other pathogenic microbes. ${ }^{76}$ More importantly, recent analysis of cellular entry into the mesenteric lymph node (MLN) has demonstrated that CX3CR1-expressing lamina propria cells are unlikely to migrate to the MLN and that these cells have poor immunostimulatory capacity. ${ }^{67}$ Thus, CX3CR1 ${ }^{+}$cells most likely represent a population of non-migrating phagocytes that provide innate immune defense against infection within the lamina propria. Given these significant issues, it remains unclear whether this alternative pathway of entry has an important physiological role, either in promoting bacterial dissemination of Salmonella or in initiating immune activation. The relative contribution of this pathway to bacterial entry and dissemination deserves further study, but it is vitally important that these studies be conducted in the context of unmanipulated mice using wild-type bacterial strains. Surprisingly, the role of cell-mediated uptake has not been examined carefully in PPs or in SILTs, yet phagocyte populations are often found in close association with the epithelial layer in each of these tissues. ${ }^{61,77}$ In summary, the available data support a prominent role for $\mathrm{M}$ cell-mediated intestinal entry by Salmonella, both in the PPs and SILTs. Salmonella entry of the lamina propria of unmanipulated mice is less well defined and the mechanisms associated with this route of entry remain largely speculative.

\section{Salmonella infection of MLNs and systemic tissues}

After Salmonella have gained entry into intestinal lymphoid tissues through $\mathrm{M}$ cells, it is believed that they travel through afferent lymphatics to the draining MLNs, and subsequently disseminate through efferent lymphatics to the blood and systemic tissues. ${ }^{78,79}$ The evidence for this step-wise migration is largely based on our understanding of the flow of lymph and the circumstantial finding that bacteria are initially detected in PPs, followed by the MLN, and finally in the spleen and liver. ${ }^{4,49}$ The trafficking of Salmonella from PPs and SILTs to MLNs is most likely accomplished by migration of infected DCs as MLN bacteria were found to be associated with $\mathrm{CD} 11 \mathrm{c}^{+}$cells, and the number of bacteria in the MLN was also reduced in C-C chemokine receptor (CCR)7-deficient mice. ${ }^{80}$ However, other studies have noted the migration of free bacteria in the afferent lymph, suggesting that some bacteria in the MLN may arrive in an extracellular form. ${ }^{78}$ After reaching the MLN, Salmonella can access efferent lymphatics and spread to systemic tissues through the thoracic duct and blood. ${ }^{78,79}$ It is not yet clear which cell population mediates this transport of bacteria to the blood and other tissues; however, intestinal DCs are usually discussed as a possibility. In a large animal model that allowed visualization of bacterial transport, the majority of Salmonella were found free in the lymph or were associated with non-DC phagocytes, ${ }^{81}$ but it is not clear whether this also occurs during exit from the MLN. Therefore, greater analysis of lymph-mediated transport of Salmonella from the MLN to the blood is required.

Disseminated Salmonella show a tropism for tissues that contain a high number of phagocytic cells, and in most circumstances, this involves the spleen, liver, and bone marrow. ${ }^{51,78}$ Bacteria are found to be closely associated with mononuclear phagocytes and to induce further recruitment or expansion of monocytic/macrophage cells in each of these locations. ${ }^{51,78}$ Salmonella also disrupt erythropoiesis, and splenomegaly can be explained in large part by the expansion of immature erythrocytes in the spleen in an erythropoietin-dependent manner. ${ }^{82}$ Cancer studies in mice have demonstrated that Salmonella preferentially accumulate in primary and metastatic tumors, ${ }^{83,84}$ suggesting that bacteria do not have a precise organ tropism other than finding tissues that contain a sufficient number of cells that support bacterial replication. Although Salmonella will continue to colonize PPs and MLNs, the large size of the spleen, liver, and bone marrow means that these tissues gradually comprise the major sites of bacterial replication. ${ }^{4,49}$ Thus, although Salmonella may be described as an intestinal pathogen, it leads to a systemic infection in mice that simply uses intestinal lymphoid tissues as a portal of entry. This also means that clearance of bacteria from the host and resistance to secondary Salmonella infection requires the coordinated action of both systemic and mucosal immunity.

\section{INITIAL BACTERIAL REPLICATION ANDTHE INNATE IMMUNE RESPONSETO SALMONELLA}

After phagocytosis by macrophages, Salmonella survive and replicate within modified intracellular vesicles, termed "Salmonella-containing vacuoles." ${ }^{85,86}$ Infected macrophages 
can be activated to kill or limit the replication of Salmonella by producing lysomal enzymes, reactive oxygen intermediates, reactive nitrogen intermediates, and other antimicrobial peptides. ${ }^{87,88}$ The ability of Salmonella to survive within the phagosome is mediated by Salmonella Pathogenicity Island 2 (SPI-2), which encodes a type-III secretion system, which prevents movement of reactive nitrogen intermediates and reactive oxygen intermediates into the phagosome where Salmonella reside. ${ }^{87,89}$ In addition, the Salmonella phoP/phoQ regulon inhibits fusion of the Salmonella-containing vacuole with toxic lysosomes and endosomes. ${ }^{90,91}$ Mice expressing the wild-type allele for the solute carrier family 11a member 1 Slc11a1 gene, which enables macrophages to transport ions into the Salmonella-containing vacuole, are more resistant to infection with Salmonella. ${ }^{92}$ In contrast, mice expressing the susceptible allele of the same gene are innately susceptible to very-low-dose infection ( $<10$ bacteria) and succumb to infection within 7-10 days of oral infection. ${ }^{29}$ Intracellular survival within tissue phagocytes is key to the virulence of Salmonella, and mutants that cannot survive and replicate within macrophages are severely attenuated for virulence. ${ }^{93}$

The initial invasion of PPs and SILTs induces a massive inflammatory response, characterized by recruitment of neutrophils, DCs, inflammatory monocytes, and macrophages. ${ }^{61,94}$ Neutrophils are believed to be important in preventing dissemination of the bacteria from the intestine to systemic tissues, and patients with reduced numbers of neutrophils have increased risk of bacteremia during infection with non-typhoidal strains of Salmonella. ${ }^{95,96}$ It has also been found that depletion of neutrophils allows Salmonella to grow extracellularly, ${ }^{97}$ suggesting that neutrophils confine and reduce bacterial replication immediately after entry. Inflammatory monocytes are also important during the initial stages of infection in the PPs and MLNs, and are an important source of anti-microbial factors, such as tumor necrosis factor- $\alpha$ and inducible nitric oxide synthase. ${ }^{94}$ Recruitment of these inflammatory cells is driven by Myd88-dependent chemokine production initiated within the PP. ${ }^{98}$ Indeed, Salmonella express several pathogen-associated molecular patterns, including lipopolysaccharide and flagellin, which can be detected by Toll-like receptors (TLRs) expressed by enterocytes and phagocytes. ${ }^{99} \mathrm{In}$ addition, macrophages can sense cytosolic flagellin using NLRC4 (also known as Ipaf, or IL-1 $\beta$-converting enzyme-protease activating factor), which activates caspase- 1 and induces the production of the proinflammatory cytokine IL-18. ${ }^{100-103}$

DCs are professional antigen-presenting cells and respond to recognition of Salmonella lipopolysaccharide or flagellin by increasing the expression of major histocompatibility complex class II and the co-stimulatory molecules CD80, CD86, and CD40. ${ }^{104,105}$ This maturation process allows DCs to efficiently present antigen to naive CD4 T cells, thus providing a vital link between innate immune responses and the induction of adaptive immunity. In the PP, flagellin also induces the secretion of the inflammatory chemokine CCL20, which is an important ligand for CCR6. ${ }^{106}$ This inflammatory response rapidly recruits CCR6-expressing DCs to the FAE, a very early process that is required for efficient activation of CD4 T cells in the $\mathrm{PP}^{50}$

\section{ADAPTIVE IMMUNE RESPONSE TO SALMONELLA Early T-cell activation in the intestine}

Given the small size of intestinal lymphoid tissues and the low frequency of naive $\mathrm{CD} 4 \mathrm{~T}$ cells specific for any given antigen, ${ }^{107}$ detecting initial Salmonella-specific T-cell activation in these tissues is challenging. However, a number of studies have used T-cell receptor transgenic mice to visualize the earliest processes of Salmonella-specific CD4 T cells responding to oral infection. ${ }^{49,108}$ Although these studies use an artificially elevated naive precursor frequency of CD4 T cells and a high dose of infection to assist visualization, they still provide the most accurate assessment of Salmonella-specific CD4 T-cell activation. ${ }^{109}$ Taken together, these studies concur that the earliest Salmonellaspecific CD4 T-cell activation occurs within the PP and is initiated around 3-6h of infection. ${ }^{49,108}$ Early activation of CD4 $\mathrm{T}$ cells requires the presence of $\mathrm{CD} 11 \mathrm{c}^{+} \mathrm{DCs}$ in the PP and is dependent on the expression of CCR6 to recruit DCs to the FAE. ${ }^{50}$ Interestingly, the T-cell receptor transgenic mouse used most frequently in these experiments recognizes a Salmonella peptide from the carboxy terminal region of flagellin, ${ }^{110}$ which as noted above is also a ligand for TLR5. ${ }^{111}$ It is generally assumed that the very early activation of flagellin-specific CD4 $\mathrm{T}$ cells in the PP is representative of the naive CD4 response to other Salmonella antigens. ${ }^{109,112}$ However, this is difficult to demonstrate conclusively as very few natural Salmonella major histocompatibility complex class-II peptides are known. ${ }^{113}$ In more recent studies, the kinetics of flagellin-specific CD4 T-cell activation was found to be delayed in mice lacking TLR5, adding support to the idea that TLR5 ligation preferentially enhances the adaptive response to flagellin in vivo. ${ }^{114}$

Salmonella-specific T cells also become activated in the MLN after oral infection, but this response usually peaks $\sim 3 \mathrm{~h}$ after that in the PP. ${ }^{49,50}$ At these very early time points, Salmonellaspecific $\mathrm{CD} 4 \mathrm{~T}$ cells were not found to be activated in any other secondary lymphoid tissue. ${ }^{49,50}$ This is important because it suggests that whatever the explanation for early bacterial dissemination to blood as discussed above, this does not initiate an early adaptive immune response outside the gut-associated lymphoid tissue. Interestingly, activation of Salmonella-specific CD4 T cells in the MLN is also dependent on CD11 $\mathrm{c}^{+} \mathrm{DCs}$ and CCR6, indicating that T-cell activation in the MLN and PP has similar requirements. There is clear evidence that suggests that the MLNs are an important site for immune protection during the course of Salmonella infection. Indeed, mice that have had MLNs surgically removed suffer from elevated bacterial loads and severe immunopathology in the liver. ${ }^{80}$ The importance of the MLN was also highlighted using a relapsing model of murine typhoid in which primary infection returns after apparent antibiotic clearance. ${ }^{28}$ Mice without MLNs had increased bacterial numbers in systemic tissues after the relapse of primary Salmonella infection. ${ }^{28}$ Thus, although the MLN is often considered a potential site of bacterial persistence, ${ }^{26,115}$ it actually provides an important protective function as a firewall preventing bacterial dissemination in primary and relapsing Salmonella infection. 


\section{DEVELOPMENT OF EFFECTOR RESPONSES AGAINST SALMONELLA}

Despite the fact that Salmonella is an intracellular pathogen, the development of robust protective immunity requires the coordinated activity of B and T cells in susceptible mice. ${ }^{116}$ In this model, CD4 T cells have a critical role in clearing primary Salmonella infection and are also required for acquired resistance to secondary infection. ${ }^{117-119}$ In contrast, B cells are dispensable for resolving primary Salmonella infection but are required for protection against secondary challenge. ${ }^{120-122}$

\section{CD4 T cells}

The development of Salmonella-specific CD4 effector responses has been examined in both susceptible and resistant mice. Taken together, these studies suggest massive expansion of Salmonellaspecific CD4 T cells and rapid acquisition of Th1 effector functions, namely the enhanced ability to secrete interferon- $\gamma$, tumor necrosis factor- $\alpha$, and IL- 2 upon restimulation. ${ }^{123-125}$ These activated Th1 cells can be clearly detected $\sim 1$ week after Salmonella infection, ${ }^{124}$ consistent with the rapid tempo of CD4 T-cell activation described in studies mentioned above. Optimal expansion of these Th1 cells has been shown to require expression of both Programmed Death Ligand-1 (PD-L1) and the tumor necrosis factor receptor family members, OX40 and CD30, ${ }^{126,127}$ although the timing and context in which these particular signals are delivered is not yet clear. Appropriately activated Th1 cells will continue to expand and can eventually comprise $\sim 50 \%$ of all CD4 T cells around 2-3 weeks after infection. ${ }^{124}$ Furthermore, these effector Th1 cells acquire the capability to rapidly secrete cytokines in response to innate signals such as lipopolysaccharide, ${ }^{128}$ although it is not clear whether $\mathrm{T}$ cells respond directly or indirectly to this inflammatory stimulus. This innate activation is unexpected as effector Th1 cells are normally considered to be stimulated to produce effector cytokines only after recognition of cognate peptide and major histocompatibility complex. ${ }^{129}$ A similar capacity to respond to innate stimuli has been reported for activated CD8 $\mathrm{T}$ cells during viral infection and has been shown to involve increased sensitivity to local IL-12 and IL-18. ${ }^{130,131}$ This innate immune responsiveness of Salmonellaspecific CD4 T cells suggests a means by which the host can rapidly produce interferon- $\gamma$ to activate macrophages within an infected tissue, even if bacteria are capable of inhibiting antigen presentation by infected phagocytes ${ }^{132-134}$ (Figure 3).

However, despite the rapid and efficient development of a large number of CD4 Th1 effector cells during primary Salmonella infection, there is actually very little evidence to suggest that they contribute to bacterial clearance at this early stage of infection. Thus, mice that completely lack all CD4 or CD4 Th1 cells will only display enhanced bacterial growth $\sim 3$ weeks after infection, ${ }^{119,135}$ indicating that Th1 cells do very little to regulate bacterial growth before this point. This confusing finding can be explained by active inhibition of the early Th1 effector response by replicating bacteria in vivo. It is important to emphasize the fact that this inhibitory effect is on expanded effector Th1 cells rather than an effect on the initial activation of naive T cells. Although many in vitro studies would point

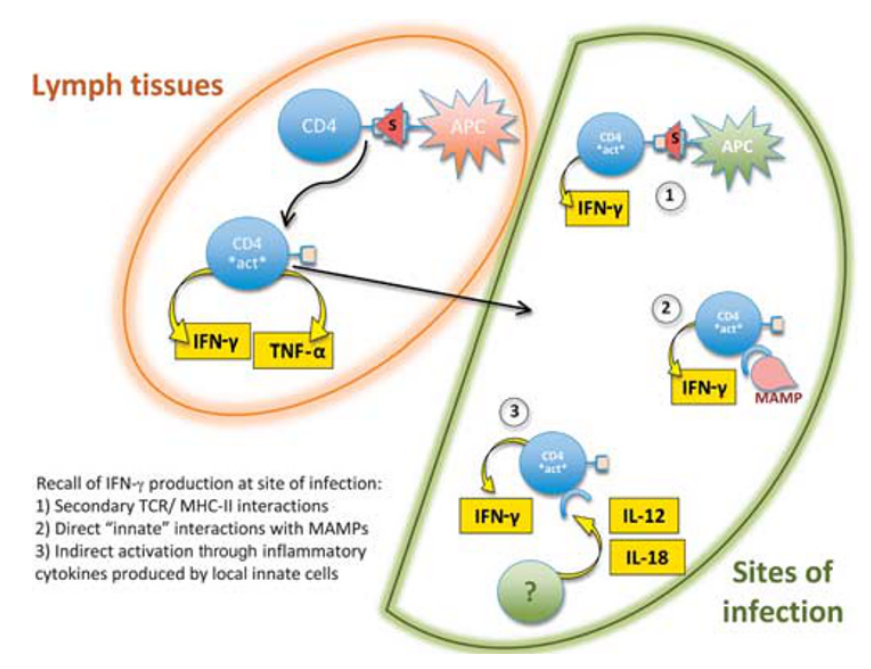

Figure 3 Salmonella-specific CD4 T cells acquire the capacity to produce IFN- $\gamma$ in response to various stimuli. Salmonella infection induces the expansion of antigen-specific CD4 T cells in secondary lymphoid tissues. These activated CD4 T cells acquire the ability to home to sites of infection and produce IFN- $\gamma$ to activate infected macrophages. Restimulation of these activated $\left(\mathrm{CD} 11 \mathrm{a}^{\mathrm{HI}}\right)$ Salmonella-specific CD4 T cells can occur (1) after ligation of the TCR, or can be initiated by bacterial products, such as LPS. It is not yet clear whether this involves (2) direct recognition of PAMPs by activated T cells or (3) a response to inflammatory mediators such as IL-12 and IL-18. IFN- $\gamma$, interferon $-\gamma$; IL, interleukin; LPS, lipopolysaccharide; PAMP, pathogen-associated molecular pattern; TCR, T-cell receptor.

to an inhibitory effect of Salmonella on antigen presentation to naive T cells in vitro, ${ }^{132,136-138}$ this does not seem to affect Salmonella-specific CD4 expansion in vivo. ${ }^{50,124,139}$ In contrast, the gradual loss of effector CD4 T cells has been detected in Salmonella-infected mice in a process that required the presence of live bacteria and the expression of SPI-2 genes. ${ }^{140}$ Therefore, even though a large population of Salmonella-specific Th1 cells is generated very early after infection with Salmonella, the effector function of these cells is actively and specifically inhibited by replicating bacteria.

\section{Treg and Th17 cells}

Although many studies have demonstrated the importance of Th1 cells in protective immunity to Salmonella, ${ }^{135,141,142}$ recent studies have also suggested a contribution by other effector CD4 subsets including regulatory T cells (Tregs) and Th17 cells. Tregs suppress effector T-cell responses and either arise from the thymus or develop after activation of naive $\mathrm{T}$ cells in the presence of transforming growth factor- $\beta .{ }^{143}$ In contrast, Th17 cells arise after stimulation of naive CD4 T cells in the presence of IL- 6 and transforming growth factor- $\beta$ and are important in mediating immunity to extracellular bacterial infections. ${ }^{144,145}$ A recent study examined the development of Th1 cells and Tregs after Salmonella infection of resistant mice and found that alterations in the potency of Tregs during infection reduced the effectiveness of Th1 responses and increased bacterial growth. ${ }^{125}$ It is not yet clear whether similar alterations in Treg potency can affect the function of Th1 responses in the susceptible mouse model or in humans. 
After oral infection with Salmonella, cytokines associated with Th17 cells, IL-17, and IL-22, are rapidly produced within the intestinal mucosa. ${ }^{146,147}$ In these studies, IL-17 and IL-22 production is induced by innate responses to bacterial infection rather than Th17 cells; however, they still indicate the potential for Th17 cytokines to participate in intestinal defense against Salmonella. Indeed, IL-17-deficient mice were reported to develop increased bacterial loads in systemic tissues compared with wild-type control mice. ${ }^{148}$ In a subsequent study, IL-23dependent production of IL-22, rather than IL-17, was found to contribute to bacterial clearance in vivo. ${ }^{149}$ Taken together, these studies suggest an important additional contribution of Th17 cells to protection against Salmonella infection. A Th17 response might be protective by initiating or enhancing neutrophil infiltration to intestinal tissues. Indeed, it was found that IL-17-deficient mice exhibited a defect in the ability to recruit neutrophils to sites of infection during Salmonella infection. ${ }^{147}$ Interestingly, highly susceptible SIV (simian immunodeficiency virus)-infected macaques were found to have a deficiency in IL-17 and IL-22, but not in interferon- $\gamma,{ }^{147}$ perhaps indicating that Th17 cells represent an important effector cell population particularly in the intestinal mucosa. In addition to neutrophil recruitment, Th17 cytokines induce production of antimicrobial peptides by epithelial cells that are effective against lumenal bacteria. ${ }^{9}$ Indeed, during Salmonella infection of rhesus macaques, IL-22 was important in the production of lipocalin-2, which prevents iron acquisition by bacteria. ${ }^{150}$ In summary, recent data have suggested an additional role for Th17 cells in defense against Salmonella in the intestine and a role for Tregs in modulating the potency of Salmonella-specific Th1 cells in vivo. Greater study of each of these T-helper populations in the mouse model of Salmonella infection and in human Salmonellosis is warranted.

\section{PROTECTIVE ANTIBODY RESPONSE AGAINST SALMONELLA}

As noted above, there is good evidence from human infections and the mouse model that suggests that Salmonella-specific B-cell responses can contribute to bacterial clearance. ${ }^{39,120,121}$ However, the mechanism by which B cells contribute to protective immunity against Salmonella remains unclear.

Although Salmonella are generally found within Salmonellacontaining vacuoles in phagocytic cells, there is a short period during the infection cycle when bacteria are expected to be extracellular. Salmonella are tightly associated with mononuclear phagocytes in vivo, ${ }^{70,85,86}$ but also induce these infected cells to undergo apoptosis. ${ }^{55}$ After this cell death, bacteria are presumably found in the extracellular compartment before infecting a neighboring phagocyte. Therefore, it is possible that antibody has direct access to Salmonella during this short period of time and prevents cell-to-cell transmission. ${ }^{109}$ Indeed, opsonization of bacteria with Salmonella-specific antibody impeded bacterial colonization in vivo. ${ }^{151}$ Antibody has also been suggested to have an important role in amplifying the processing and presentation of Salmonella antigens to CD4 T cells, thus affecting the quantity and quality of the Th1 response. ${ }^{152,153}$ Innate B-cell responses to
TLR ligands have also been shown to be important for the development of Th1 responses in vivo, ${ }^{154,155}$ suggesting another route by which effector T-cell development can be regulated by B-cell responses to Salmonella. However, recent work suggests that B-cell signaling through MyD88 can also suppress the development of protective immunity during Salmonella infection. ${ }^{156}$ Thus, the role of innate immune signaling in B cells serves an important regulatory function but requires further analysis. The presence of Salmonella-specific IgA in the intestinal mucosa may also prevent or reduce bacterial penetration of the intestinal barrier. ${ }^{157}$ It is not yet clear which of these mechanisms makes the greatest contribution to protective immunity to Salmonella infection but an important role for antibody is also suggested from human studies. ${ }^{158}$ Although the specificity of these antibody responses are mostly undefined, antibodies specific for the lipopolysaccharide $\mathrm{O}$-antigen, flagellin, the ViCPS antigen, and OmpD are all believed to be protective. ${ }^{116,159}$

\section{CONCLUDING REMARKS}

Immunologists and microbiologists have long appreciated murine infection with Salmonella as a model that allows a natural route of challenge and detailed study of bacterial virulence factors and innate and adaptive immunity. The powerful genetic and immunological tools that are available in this model make it ideal for dissecting the complicated issues of bacterial pathogenesis and immunity to infection. Despite the uncertainty of translating murine data to human typhoid or NTS, it is likely that each of these infections has similar immunological aspects as all three involve disseminated Salmonellosis. Bacterial entry is a complex process involving the interaction of bacterial SPI-1 gene products with M cells overlying PPs and SILTs. Recent data have suggested that protective immunity requires coordinated interaction of Salmonella-specific Th1 and Th17 cells and the activation of Salmonella-specific B cells. Interestingly, this combined requirement bears many similarities to data examining the dissemination of NTS in humans. Greater study of the immune parameters associated with protection in the mouse model is therefore likely to inform the generation of new vaccines against disseminated Salmonella infections in humans.

\section{ACKNOWLEDGMENTS}

We thank Drs Sing-Sing Way, Adam Cunningham, and Oliver Pabst for critical reading of this manuscript and numerous helpful suggestions. We also thank Hope O'Donnell and Josh McCarra for designing and preparing Figures. This work was supported by grants from the National Institutes of Health to SJM (AI055743 and AI56172).

\section{DISCLOSURE}

The authors declared no conflict of interest.

(C) 2011 Society for Mucosal Immunology

\section{REFERENCES}

1. Mead, P.S. et al. Food-related illness and death in the United States. Emerg. Infect. Dis. 5, 607-625 (1999).

2. Levine, M.M. Enteric infections and the vaccines to counter them: future directions. Vaccine 24, 3865-3873 (2006).

3. Crump, J.A. \& Mintz, E.D. Global trends in typhoid and paratyphoid fever. Clin. Infect. Dis. 50, 241-246 (2010). 
4. Carter, P.B. \& Collins, F.M. The route of enteric infection in normal mice. J. Exp. Med. 139, 1189-1203 (1974)

5. Zinkernagel, R.M. Cell-mediated immune response to Salmonella typhimurium infection in mice: development of nonspecific bactericidal activity against Listeria monocytogenes. Infect. Immun. 13, 1069-1073 (1976).

6. Mittrucker, H.W. \& Kaufmann, S.H. Immune response to infection with Salmonella typhimurium in mice. J. Leukoc. Biol. 67, 457-463 (2000).

7. Mastroeni, P., Chabalgoity, J.A., Dunstan, S.J., Maskell, D.J. \& Dougan, G. Salmonella: immune responses and vaccines. Vet. J. 161, 132-164 (2001).

8. Monack, D.M., Mueller, A. \& Falkow, S. Persistent bacterial infections: the interface of the pathogen and the host immune system. Nat. Rev. Microbiol. 2, 747-765 (2004).

9. Santos, R.L. et al. Life in the inflamed intestine, Salmonella style. Trends Microbiol. 17, 498-506 (2009).

10. Andrews-Polymenis, H.L., Baumler, A.J., McCormick, B.A. \& Fang, F.C. Taming the elephant: Salmonella biology, pathogenesis, and prevention. Infect. Immun. 78, 2356-2369 (2010).

11. Parry, C.M., Hien, T.T., Dougan, G., White, N.J. \& Farrar, J.J. Typhoid fever. N. Engl. J. Med. 347, 1770-1782 (2002).

12. Centers for Disease Control and Prevention (CDC). Multistate outbreaks of Salmonella infections associated with raw tomatoes eaten in restaurants-United States, 2005-2006. MMWR Morb. Mortal. Wkly Rep. 56, 909-911 (2007).

13. Centers for Disease Control and Prevention (CDC). Outbreak of Salmonella serotype Saintpaul infections associated with multiple raw produce items - United States, 2008. MMWR Morb. Mortal. Wkly Rep. 57, 929-934 (2008).

14. Centers for Disease Control and Prevention (CDC). Multistate outbreak of Salmonella infections associated with peanut butter and peanut butter-containing products-United States, 2008-2009. MMWR Morb. Mortal. Wkly Rep. 58, 85-90 (2009).

15. Olsen, S.J., MacKinnon, L.C., Goulding, J.S., Bean, N.H. \& Slutsker, L. Surveillance for food-borne-disease outbreaks - United States, 1993-1997. MMWR CDC Surveill. Summ. 49, 1-62 (2000).

16. Nyachuba, D.G. Food-borne illness: is it on the rise? Nutr. Rev. 68, 257-269 (2010).

17. Crump, J.A., Luby, S.P. \& Mintz, E.D. The global burden of typhoid fever. Bull. World Health Organ. 82, 346-353 (2004).

18. Clasen, T., Schmidt, W.P., Rabie, T., Roberts, I. \& Cairncross, S. Interventions to improve water quality for preventing diarrhoea: systematic review and meta-analysis. BMJ 334, 782 (2007).

19. Mara, D.D. Water, sanitation and hygiene for the health of developing nations. Public Health 117, 452-456 (2003).

20. Fraser, A., Paul, M., Goldberg, E., Acosta, C.J. \& Leibovici, L. Typhoid fever vaccines: systematic review and meta-analysis of randomised controlled trials. Vaccine 25, 7848-7857 (2007).

21. Bhan, M.K., Bahl, R. \& Bhatnagar, S. Typhoid and paratyphoid fever. Lancet 366, 749-762 (2005).

22. Gotuzzo, E. et al. Association between specific plasmids and relapse in typhoid fever. J. Clin. Microbiol. 25, 1779-1781 (1987).

23. Yew, F.S., Chew, S.K., Goh, K.T., Monteiro, E.H. \& Lim, Y.S. Typhoid fever in Singapore: a review of 370 cases. J. Trop. Med. Hyg. 94, 352-357 (1991).

24. Smith, M.D. et al. Comparison of ofloxacin and ceftriaxone for shortcourse treatment of enteric fever. Antimicrob. Agents Chemother. 38, 1716-1720 (1994).

25. Wain, J. et al. Molecular typing of multiple-antibiotic-resistant Salmonella enterica serovar Typhi from Vietnam: application to acute and relapse cases of typhoid fever. J. Clin. Microbiol. 37, 2466-2472 (1999).

26. Monack, D.M., Bouley, D.M. \& Falkow, S. Salmonella typhimurium persists within macrophages in the mesenteric lymph nodes of chronically infected Nramp1+/+ mice and can be reactivated by IFNgamma neutralization. J. Exp. Med. 199, 231-241 (2004).

27. Crawford, R.W., Rosales-Reyes, R., Ramirez-Aguilar Mde, L., ChapaAzuela, O., Alpuche-Aranda, C. \& Gunn, J.S. Gallstones play a significant role in Salmonella spp. gallbladder colonization and carriage. Proc. Natl Acad. Sci. USA 107, 4353-4358 (2010).

28. Griffin, AJ., Li, LX., Voedisch, S., Pabst, O. \& McSorley, S.J. Dissemination of persistent intestinal bacteria via the mesenteric lymph nodes causes typhoid relapse. Infect. Immun. (e-pub ahead of print 24 January 2011).
29. Griffin, A., Baraho-Hassan, D. \& McSorley, S.J. Successful treatment of bacterial infection hinders development of acquired immunity. J. Immunol. 183, 1263-1270 (2009).

30. Gordon, M.A. Salmonella infections in immunocompromised adults. J. Infect. 56, 413-422 (2008).

31. Graham, S.M., Molyneux, E.M., Walsh, A.L., Cheesbrough, J.S., Molyneux, M.E. \& Hart, C.A. Nontyphoidal Salmonella infections of children in tropical Africa. Pediatr. Infect. Dis. J. 19, 1189-1196 (2000).

32. Brent, A.J., Oundo, J.O., Mwangi, I., Ochola, L., Lowe, B. \& Berkley, J.A. Salmonella bacteremia in Kenyan children. Pediatr. Infect. Dis. J. 25, 230-236 (2006)

33. Kariuki, S., Revathi, G., Gakuya, F., Yamo, V., Muyodi, J. \& Hart, C.A. Lack of clonal relationship between non-typhi Salmonella strain types from humans and those isolated from animals living in close contact. FEMS Immunol. Med. Microbiol. 33, 165-171 (2002).

34. Kingsley, R.A. et al. Epidemic multiple drug resistant Salmonella Typhimurium causing invasive disease in sub-Saharan Africa have a distinct genotype. Genome Res. 19, 2279-2287 (2009).

35. Chierakul, W. et al. The changing pattern of bloodstream infections associated with the rise in HIV prevalence in northeastern Thailand. Trans. R. Soc. Trop. Med. Hyg. 98, 678-686 (2004).

36. Peters, R.P. et al. A prospective study of bloodstream infections as cause of fever in Malawi: clinical predictors and implications for management. Trop. Med. Int. Health 9, 928-934 (2004).

37. Gordon, M.A. et al. Invasive non-typhoid salmonellae establish systemic intracellular infection in HIV-infected adults: an emerging disease pathogenesis. Clin. Infect. Dis. 50, 953-962 (2010).

38. van de Vosse, E. \& Ottenhoff, T.H. Human host genetic factors in mycobacterial and Salmonella infection: lessons from single gene disorders in IL-12/IL-23-dependent signaling that affect innate and adaptive immunity. Microbes Infect. 8, 1167-1173 (2006).

39. MacLennan, C.A. et al. The neglected role of antibody in protection against bacteremia caused by nontyphoidal strains of Salmonella in African children. J. Clin. Invest. 118, 1553-1562 (2008).

40. Santos, R.L., Zhang, S., Tsolis, R.M., Kingsley, R.A., Adams, L.G. \& Baumler, A.J. Animal models of salmonella infections: enteritis versus typhoid fever. Microbes Infect. 3, 1335-1344 (2001).

41. Barthel, M. et al. Pretreatment of mice with streptomycin provides a Salmonella enterica serovar Typhimurium colitis model that allows analysis of both pathogen and host. Infect. Immun. 71, 2839-2858 (2003).

42. Hapfelmeier, S. \& Hardt, W.D. A mouse model for S. typhimuriuminduced enterocolitis. Trends Microbiol. 13, 497-503 (2005).

43. Pasetti, M.F., Levine, M.M. \& Sztein, M.B. Animal models paving the way for clinical trials of attenuated Salmonella enterica serovar Typhi live oral vaccines and live vectors. Vaccine 21, 401-418 (2003).

44. Galan, J.E. \& Curtiss, R. III. Cloning and molecular characterization of genes whose products allow Salmonella typhimurium to penetrate tissue culture cells. Proc. Natl Acad. Sci. USA 86, 6383-6387 (1989).

45. Fierer, J. \& Guiney, D.G. Diverse virulence traits underlying different clinical outcomes of Salmonella infection. J. Clin. Invest. 107, 775-780 (2001).

46. McSorley, S.J., Xu, D. \& Liew, F.Y. Vaccine efficacy of Salmonella strains expressing glycoprotein 63 with different promoters. Infect. Immun. 65, 171-178 (1997).

47. Jones, B.D., Ghori, N. \& Falkow, S. Salmonella typhimurium initiates murine infection by penetrating and destroying the specialized epithelial M cells of the Peyer's patches. J. Exp. Med. 180, 15-23 (1994).

48. Hohmann, A.W., Schmidt, G. \& Rowley, D. Intestinal colonization and virulence of Salmonella in mice. Infect. Immun. 22, 763-770 (1978).

49. McSorley, S.J., Asch, S., Costalonga, M., Rieinhardt, R.L. \& Jenkins, M.K. Tracking Salmonella-specific CD4 T cells in vivo reveals a local mucosal response to a disseminated infection. Immunity 16, 365-377 (2002)

50. Salazar-Gonzalez, R.M. et al. CCR6-mediated dendritic cell activation of pathogen-specific T cells in Peyer's patches. Immunity 24, 623-632 (2006).

51. Jones, B.D. \& Falkow, S. Salmonellosis: host immune responses and bacterial virulence determinants. Annu. Rev. Immunol. 14, 533-561 (1996).

52. Francis, C.L., Ryan, T.A., Jones, B.D., Smith, S.J. \& Falkow, S. Ruffles induced by Salmonella and other stimuli direct macropinocytosis of bacteria. Nature 364, 639-642 (1993). 
53. Baumler, A.J., Tsolis, R.M. \& Heffron, F. The lpf fimbrial operon mediates adhesion of Salmonella typhimurium to murine Peyer's patches. Proc. Natl Acad. Sci. USA 93, 279-283 (1996).

54. Hase, K. et al. Uptake through glycoprotein 2 of FimH(+) bacteria by $\mathrm{M}$ cells initiates mucosal immune response. Nature 462, 226-230 (2009).

55. van der Velden, A.W., Velasquez, M. \& Starnbach, M.N. Salmonella rapidly kill dendritic cells via a caspase-1-dependent mechanism. J. Immunol. 171, 6742-6749 (2003).

56. Fink, S.L. \& Cookson, B.T. Apoptosis, pyroptosis, and necrosis: mechanistic description of dead and dying eukaryotic cells. Infect. Immun. 73, 1907-1916 (2005).

57. Fernandes-Alnemri, T. et al. The pyroptosome: a supramolecular assembly of ASC dimers mediating inflammatory cell death via caspase1 activation. Cell. Death Differ. 14, 1590-1604 (2007).

58. Monack, D.M., Hersh, D., Ghori, N., Bouley, D., Zychlinsky, A. \& Falkow, $\mathrm{S}$. Salmonella exploits caspase- 1 to colonize Peyer's patches in a murine typhoid model. J. Exp. Med. 192, 249-258 (2000).

59. Hamada, $\mathrm{H}$. et al. Identification of multiple isolated lymphoid follicles on the antimesenteric wall of the mouse small intestine. J. Immunol. 168, 57-64 (2002).

60. Pabst, O. et al. Adaptation of solitary intestinal lymphoid tissue in response to microbiota and chemokine receptor CCR7 signaling J. Immunol. 177, 6824-6832 (2006).

61. Halle, S. et al. Solitary intestinal lymphoid tissue provides a productive port of entry for Salmonella enterica serovar Typhimurium. Infect. Immun. 75, 1577-1585 (2007).

62. Herbrand, H., Bernhardt, G., Forster, R. \& Pabst, O. Dynamics and function of solitary intestinal lymphoid tissue. Crit. Rev. Immunol. 28 , 1-13 (2008)

63. Kraus, M.D., Amatya, B. \& Kimula, Y. Histopathology of typhoid enteritis: morphologic and immunophenotypic findings. Mod. Pathol. 12, 949-955 (1999).

64. Jang, M.H. et al. Intestinal villous M cells: an antigen entry site in the mucosal epithelium. Proc. Natl Acad. Sci. USA 101, 6110-6115 (2004).

65. Martinoli, C., Chiavelli, A. \& Rescigno, M. Entry route of Salmonella typhimurium directs the type of induced immune response. Immunity $\mathbf{2 7}$, 975-984 (2007).

66. Niess, J.H. \& Reinecker, H.C. Dendritic cells in the recognition of intestinal microbiota. Cell. Microbiol. 8, 558-564 (2006).

67. Schulz, O. et al. Intestinal CD103+, but not CX3CR1+, antigen sampling cells migrate in lymph and serve classical dendritic cell functions. J. Exp. Med. 206, 3101-3114 (2009).

68. Persson, E.K., Jaensson, E. \& Agace, W.W. The diverse ontogeny and function of murine small intestinal dendritic cell/macrophage subsets. Immunobiology 215, 692-697 (2010).

69. Pabst, O. \& Bernhardt, G. The puzzle of intestinal lamina propria dendritic cells and macrophages. Eur. J. Immunol. 40, 2107-2111 (2010).

70. Vazquez-Torres, A. et al. Extraintestinal dissemination of Salmonella by CD18-expressing phagocytes. Nature 401, 804-808 (1999).

71. Gerichter, C.B. The dissemination of Salmonella typhi, S. paratyphi A and $S$. paratyphi $B$ through the organs of the white mouse by oral infection. J. Hyg. (Lond) 58, 307-319 (1960).

72. Worley, M.J., Nieman, G.S., Geddes, K. \& Heffron, F. Salmonella typhimurium disseminates within its host by manipulating the motility of infected cells. Proc. Natl Acad. Sci. USA 103, 17915-17920 (2006).

73. Rescigno, M. et al. Dendritic cells express tight junction proteins and penetrate gut epithelial monolayers to sample bacteria. Nat. Immunol. 2, 361-367 (2001).

74. Niess, J.H. et al. CX3CR1-mediated dendritic cell access to the intestinal lumen and bacterial clearance. Science 307, 254-258 (2005).

75. Chieppa, M., Rescigno, M., Huang, A.Y. \& Germain, R.N. Dynamic imaging of dendritic cell extension into the small bowel lumen in response to epithelial cell TLR engagement. J. Exp. Med. 203, 2841-2852 (2006)

76. Vallon-Eberhard, A., Landsman, L., Yogev, N., Verrier, B. \& Jung, S Transepithelial pathogen uptake into the small intestinal lamina propria. J. Immunol. 176, 2465-2469 (2006).

77. Iwasaki, A. \& Kelsall, B.L. Localization of distinct Peyer's patch dendritic cell subsets and their recruitment by chemokines macrophage inflammatory protein (MIP)-3alpha, MIP-3beta, and secondary lymphoid organ chemokine. J. Exp. Med. 191, 1381-1394 (2000).
78. Tam, M.A., Rydstrom, A., Sundquist, M. \& Wick, M.J. Early cellular responses to Salmonella infection: dendritic cells, monocytes, and more. Immunol. Rev. 225, 140-162 (2008).

79. Moon, J.J. \& McSorley, S.J. Tracking the dynamics of salmonella specific T cell responses. Curr. Top. Microbiol. Immunol. 334, 179-198 (2009).

80. Voedisch, S. et al. Mesenteric lymph nodes confine dendritic cellmediated dissemination of Salmonella enterica serovar Typhimurium and limit systemic disease in mice. Infect. Immun. 77, 3170-3180 (2009).

81. Bonneau, M. et al. Migratory monocytes and granulocytes are major lymphatic carriers of Salmonella from tissue to draining lymph node. J. Leukoc. Biol. 79, 268-276 (2006).

82. Jackson, A., Nanton, M.R., O'Donnell, H., Akue, A.D. \& McSorley, S.J. Innate immune activation during Salmonella infection initiates extramedullary erythropoiesis and splenomegaly. J. Immunol. 185, 6198-6204 (2010).

83. Low, K.B. et al. Lipid A mutant Salmonella with suppressed virulence and TNFalpha induction retain tumor-targeting in vivo. Nat. Biotechnol. 17, 37-41 (1999).

84. Yu, Y.A. et al. Visualization of tumors and metastases in live animals with bacteria and vaccinia virus encoding light-emitting proteins. Nat. Biotechnol. 22, 313-320 (2004).

85. Sheppard, M. et al. Dynamics of bacterial growth and distribution within the liver during Salmonella infection. Cell. Microbiol. 5, 593-600 (2003).

86. Richter-Dahlfors, A., Buchan, A.M. \& Finlay, B.B. Murine salmonellosis studied by confocal microscopy: Salmonella typhimurium resides intracellularly inside macrophages and exerts a cytotoxic effect on phagocytes in vivo. J. Exp. Med. 186, 569-580 (1997).

87. Vazquez-Torres, A., Jones-Carson, J., Mastroeni, P., Ischiropoulos, H. \& Fang, F.C. Antimicrobial actions of the NADPH phagocyte oxidase and inducible nitric oxide synthase in experimental salmonellosis. I. Effects on microbial killing by activated peritoneal macrophages in vitro. J. Exp. Med. 192, 227-236 (2000).

88. Mastroeni, P. et al. Antimicrobial actions of the NADPH phagocyte oxidase and inducible nitric oxide synthase in experimental salmonellosis. II. Effects on microbial proliferation and host survival in vivo. J. Exp. Med. 192, 237-248 (2000)

89. Chakravortty, D., Hansen-Wester, I. \& Hensel, M. Salmonella pathogenicity island 2 mediates protection of intracellular Salmonella from reactive nitrogen intermediates. J. Exp. Med. 195, 1155-1166 (2002).

90. Miller, S.I. PhoP/PhoQ: macrophage-specific modulators of Salmonella virulence? Mol. Microbiol. 5, 2073-2078 (1991).

91. Garvis, S.G., Beuzon, C.R. \& Holden, D.W. A role for the PhoP/Q regulon in inhibition of fusion between lysosomes and Salmonella-containing vacuoles in macrophages. Cell. Microbiol. 3, 731-744 (2001).

92. White, J.K., Mastroeni, P., Popoff, J.F., Evans, C.A. \& Blackwell, J.M. Slc11a1-mediated resistance to Salmonella enterica serovar Typhimurium and Leishmania donovani infections does not require functional inducible nitric oxide synthase or phagocyte oxidase activity. J. Leukoc. Biol. 77, 311-320 (2005)

93. Fields, P.I., Swanson, R.V., Haidaris, C.G. \& Heffron, F. Mutants of Salmonella typhimurium that cannot survive within the macrophage are avirulent. Proc. Natl Acad. Sci. USA 83, 5189-5193 (1986).

94. Rydstrom, A. \& Wick, M.J. Monocyte recruitment, activation, and function in the gut-associated lymphoid tissue during oral Salmonella infection. J. Immunol. 178, 5789-5801 (2007).

95. Noriega, L.M., Van der Auwera, P., Daneau, D., Meunier, F. \& Aoun, M. Salmonella infections in a cancer center. Support Care Cancer 2, 116-122 (1994).

96. Tumbarello, M., Tacconelli, E., Caponera, S., Cauda, R. \& Ortona, L. The impact of bacteraemia on HIV infection. Nine years experience in a large Italian university hospital. J. Infect. 31, 123-131 (1995).

97. Conlan, J.W. Neutrophils prevent extracellular colonization of the liver microvasculature by Salmonella typhimurium. Infect. Immun. 64, 1043-1047 (1996)

98. Rydstrom, A. \& Wick, M.J. Monocyte and neutrophil recruitment during oral Salmonella infection is driven by MyD88-derived chemokines. Eur. J. Immunol. 39, 3019-3030 (2009).

99. Barton, G.M. \& Medzhitov, R. Toll-like receptors and their ligands. Curr. Top. Microbiol. Immunol. 270, 81-92 (2002).

100. Franchi, L. et al. Cytosolic flagellin requires Ipaf for activation of caspase1 and interleukin 1 beta in salmonella-infected macrophages. Nat. Immunol. 7, 576-582 (2006). 
101. Miao, E.A. et al. Cytoplasmic flagellin activates caspase-1 and secretion of interleukin 1 beta via Ipaf. Nat. Immunol. 7, 569-575 (2006).

102. Winter, S.E. et al. Contribution of flagellin pattern recognition to intestinal inflammation during Salmonella enterica serotype typhimurium infection. Infect. Immun. 77, 1904-1916 (2009).

103. Broz, P., Newton, K., Lamkanfi, M., Mariathasan, S., Dixit, V.M. \& Monack, D.M. Redundant roles for inflammasome receptors NLRP3 and NLRC4 in host defense against Salmonella. J. Exp. Med. 207, 1745-1755 (2010).

104. McSorley, S.J., Ehst, B.D., Yu, Y. \& Gewirtz, A.T. Bacterial flagellin is an effective adjuvant for CD4 T cells in vivo. J. Immunol. 169, 3914 (2002).

105. Salazar-Gonzalez, R.M. et al. Salmonella flagellin induces bystander activation of splenic dendritic cells and hinders bacterial replication in vivo. J. Immunol. 179, 6169-6175 (2007).

106. Sierro, F., Dubois, B., Coste, A., Kaiserlian, D., Kraehenbuhl, J.P. \& Sirard, J.C. Flagellin stimulation of intestinal epithelial cells triggers CCL2O-mediated migration of dendritic cells. Proc. Natl Acad. Sci. USA 98, 13722-13727 (2001).

107. Moon, J.J. et al. Naive CD4(+) T cell frequency varies for different epitopes and predicts repertoire diversity and response magnitude. Immunity 27, 203-213 (2007).

108. Bumann, D. In vivo visualization of bacterial colonization, antigen expression and specific T-cell induction following oral administration of live recombinant Salmonella enterica serovar typhimurium. Infect. Immun. 69, 4618-4626 (2001).

109. Ravindran, R. \& McSorley, S.J. Tracking the dynamics of T-cell activation in response to Salmonella infection. Immunology 114, 450-458 (2005).

110. McSorley, S.J., Cookson, B.T. \& Jenkins, M.K. Characterization of CD4+ T cell responses during natural infection with Salmonella typhimurium. J. Immunol. 164, 986-993 (2000).

111. Hayashi, F. et al. The innate immune response to bacterial flagellin is mediated by Toll-like receptor 5. Nature 410, 1099-1103 (2001).

112. Srinivasan, A. \& McSorley, S.J. Activation of Salmonella-specific immune responses in the intestinal mucosa. Arch. Immunol. Ther. Exp. (Warsz) 54, 25-31 (2006).

113. Letran, S.E., Lee, S.J., Atif, S.M., Uematsu, S., Akira, S. \& McSorley, S.J. TLR5 functions as an endocytic receptor to enhance flagellin - specific adaptive immunity. Eur. J. Immunol. 41, 29-38 (2011).

114. Srinivasan, A. \& McSorley, S.J. Visualizing the immune response to pathogens. Curr. Opin. Immunol. 16, 494-498 (2004).

115. Nix, R.N., Altschuler, S.E., Henson, P.M. \& Detweiler, C.S. Hemophagocytic macrophages harbor Salmonella enterica during persistent infection. PLoS Pathog. 3, e193 (2007).

116. Mastroeni, P. Immunity to systemic Salmonella infections. Curr. Mol. Med. 2, 393-406 (2002).

117. Nauciel, C. Role of CD4+ T cells and T-independent mechanisms in aquired resistance to Salmonella typhimurium infection. J. Immunol. 145, 1265-1269 (1990).

118. Sinha, K., Mastroeni, P., Harrison, J., de Hormaeche, R.D. \& Hormaeche, C.E. Salmonella typhimurium aroA, htrA, and AroD htrA mutants cause progressive infections in athymic (nu/nu) BALB/c mice. Infect. Immun. 65, 1566-1569 (1997).

119. Hess, J., Ladel, C., Miko, D. \& Kaufmann, S.H. Salmonella typhimurium aroA-infection in gene-targeted immunodeficient mice: major role of CD4+ TCR-alpha beta cells and IFN-gamma in bacterial clearance independent of intracellular location. J. Immunol. 156, 3321-3326 (1996).

120. Mastroeni, P., Simmons, C., Fowler, R., Hormaeche, C.E. \& Dougan, G. Igh-6(-/-) (B-cell-deficient) mice fail to mount solid aquired resistance to oral challenge with virulent Salmonella enterica serovar typhimurium and show impaired Th1 T-cell responses to Salmonella antigens. Infect. Immun. 68, 46-53 (2000).

121. McSorley, S.J. \& Jenkins, M.K. Antibody is required for protection against virulent but not attenuated Salmonella enterica serovar typhimurium. Infect. Immun. 68, 3344-3348 (2000).

122. Mittrucker, H.W., Raupach, B., Kohler, A. \& Kaufmann, S.H. Cutting edge: role of B lymphocytes in protective immunity against Salmonella typhimurium infection. J. Immunol. 164, 1648-1652 (2000).

123. Mittrucker, H., Kohler, A. \& Kaufmann, S.H. Characterization of the murine T-lymphocyte response to salmonella enterica serovar typhimurium infection. Infect. Immun. 70, 199-203 (2002).
124. Srinivasan, A., Foley, J. \& McSorley, S.J. Massive number of antigenspecific CD4 T cells during vaccination with live attenuated Salmonella causes interclonal competition. J. Immunol. 172, 6884-6893 (2004).

125. Johanns, T.M., Ertelt, J.M., Rowe, J.H. \& Way, S.S. Regulatory T cell suppressive potency dictates the balance between bacterial proliferation and clearance during persistent Salmonella infection. PLoS Pathog. 6, pii: e1001043 (2010).

126. Gaspal, F. et al. Critical synergy of CD30 and OX40 signals in CD4 T cell homeostasis and Th1 immunity to Salmonella. J. Immunol. 180, 28242829 (2008).

127. Lee, S.J., O'Donnell, H. \& McSorley, S.J. B7-H1 (programmed cell death ligand 1) is required for the development of multifunctional Th1 cells and immunity to primary, but not secondary, Salmonella infection. J. Immunol. 185, 2442-2449 (2010).

128. Srinivasan, A., Salazar-Gonzalez, R.M., Jarcho, M., Sandau, M.M., Lefrancois, L. \& McSorley, S.J. Innate immune activation of CD4 T cells in salmonella-infected mice is dependent on IL-18. J. Immunol. 178, 6342-6349 (2007).

129. McLachlan, J.B., Catron, D.M., Moon, J.J. \& Jenkins, M.K. Dendritic cell antigen presentation drives simultaneous cytokine production by effector and regulatory T cells in inflamed skin. Immunity 30, 277-288 (2009).

130. Beadling, C. \& Slifka, M.K. Differential regulation of virus-specific T-cell effector functions following activation by peptide or innate cytokines. Blood 105, 1179-1186 (2005).

131. Berg, R.E. \& Forman, J. The role of CD8 T cells in innate immunity and in antigen non-specific protection. Curr. Opin. Immunol. 18, 338-343 (2006).

132. Cheminay, C., Mohlenbrink, A. \& Hensel, M. Intracellular Salmonella inhibit antigen presentation by dendritic cells. J. Immunol. 174, 2892-2899 (2005).

133. Tobar, J.A. et al. Virulent Salmonella enterica serovar typhimurium evades adaptive immunity by preventing dendritic cells from activating T cells. Infect. Immun. 74, 6438-6448 (2006).

134. Rydstrom, A. \& Wick, M.J. Salmonella inhibits monocyte differentiation into CD11c hi MHC-II hi cells in a MyD88-dependent fashion. J. Leukoc. Biol. 87, 823-832.

135. Ravindran, R., Foley, J., Stoklasek, T., Glimcher, L.H. \& McSorley, S.J. Expression of T-bet by CD4 T cells is essential for resistance to Salmonella infection. J. Immunol. 175, 4603-4610 (2005).

136. Yrlid, U., Svensson, M., Johansson, C. \& Wick, M.J. Salmonella infection of bone marrow-derived macrophages and dendritic cells: influence on antigen presentation and initiating an immune response. FEMS Immunol. Med. Microbiol. 27, 313-320 (2000).

137. Tobar, J.A., Gonzalez, P.A. \& Kalergis, A.M. Salmonella escape from antigen presentation can be overcome by targeting bacteria to Fcgamma receptors on dendritic cells. J. Immunol. 173, 4058-4065 (2004).

138. Halici, S., Zenk, S.F., Jantsch, J. \& Hensel, M. Functional analysis of the Salmonella pathogenicity island 2-mediated inhibition of antigen presentation in dendritic cells. Infect. Immun. 76, 4924-4933 (2008).

139. Yrlid, U. \& Wick, M.J. Antigen presentation capacity and cytokine production by murine splenic dendritic cell subsets upon Salmonella encounter. J. Immunol. 169, 108-116 (2002).

140. Srinivasan, A., Nanton, M., Griffin, A. \& McSorley, S.J. Culling of activated CD4 T cells during typhoid is driven by Salmonella virulence genes. J. Immunol. 182, 7838-7845 (2009).

141. Mastroeni, P., Harrison, J.A., Chabalgoity, J.A. \& Hormaeche, C.E. Effect of interleukin 12 neutralization on host resistance and gamma interferon production in mouse typhoid. Infect. Immun. 64, 189-196 (1996).

142. VanCott, J.L. et al. Regulation of host immune responses by modification of Salmonella virulence genes. Nat. Med. 4, 1247-1252 (1998).

143. Xu, L., Kitani, A. \& Strober, W. Molecular mechanisms regulating TGFbeta-induced Foxp3 expression. Mucosal. Immunol. 3, 230-238 (2010).

144. Weaver, C.T., Hatton, R.D., Mangan, P.R. \& Harrington, L.E. IL-17 family cytokines and the expanding diversity of effector T cell lineages. Annu. Rev. Immunol. 25, 821-852 (2007).

145. Curtis, M.M. \& Way, S.S. Interleukin-17 in host defence against bacterial, mycobacterial and fungal pathogens. Immunology 126, 177-185 (2009).

146. Raffatellu, M. et al. The capsule encoding the viaB locus reduces interleukin-17 expression and mucosal innate responses in the bovine intestinal mucosa during infection with Salmonella enterica serotype Typhi. Infect. Immun. 75, 4342-4350 (2007). 


\section{REVIEW}

147. Raffatellu, M. et al. Simian immunodeficiency virus-induced mucosal interleukin-17 deficiency promotes Salmonella dissemination from the gut. Nat. Med. 14, 421-428 (2008).

148. Schulz, S.M., Kohler, G., Holscher, C., Iwakura, Y. \& Alber, G. IL-17A is produced by Th17, gammadelta T cells and other CD4- lymphocytes during infection with Salmonella enterica serovar Enteritidis and has a mild effect in bacterial clearance. Int. Immunol. 20, 1129-1138 (2008).

149. Schulz, S.M. et al. Protective immunity to systemic infection with attenuated Salmonella enterica serovar enteritidis in the absence of IL-12 is associated with IL-23-dependent IL-22, but not IL-17. J. Immunol. 181, 7891-7901 (2008).

150. Raffatellu, M. et al. Lipocalin-2 resistance confers an advantage to Salmonella enterica serotype Typhimurium for growth and survival in the inflamed intestine. Cell. Host Microbe 5, 476-486 (2009).

151. Cunningham, A.F. et al. Salmonella induces a switched antibody response without germinal centers that impedes the extracellular spread of infection. J. Immunol. 178, 6200-6207 (2007).

152. Ugrinovic, S., Menager, N., Goh, N. \& Mastroeni, P. Characterization and development of T-Cell immune responses in B-cell-deficient Igh-6(-/-) mice with Salmonella enterica serovar Typhimurium infection. Infect. Immun. 71, 6808-6819 (2003).
153. Bueno, S.M., Gonzalez, P.A., Schwebach, J.R. \& Kalergis, A.M. T cell immunity evasion by virulent Salmonella enterica. Immunol. Lett. 111, 14-20 (2007).

154. Barr, T.A., Brown, S., Mastroeni, P. \& Gray, D. B cell intrinsic MyD88 signals drive IFN-gamma production from T cells and control switching to IgG2c. J. Immunol. 183, 1005-1012 (2009).

155. Barr, T.A., Brown, S., Mastroeni, P. \& Gray, D. TLR and B cell receptor signals to B cells differentially program primary and memory Th1 responses to Salmonella enterica. J. Immunol. 185, 2783-2789 (2010).

156. Neves, P. et al. Signaling via the MyD88 adaptor protein in B cells suppresses protective immunity during Salmonella typhimurium infection. Immunity 33, 777-790 (2010)

157. Wijburg, O.L., Uren, T.K., Simpfendorfer, K., Johansen, F.E., Brandtzaeg, P. \& Strugnell, R.A. Innate secretory antibodies protect against natural Salmonella typhimurium infection. J. Exp. Med. 203, 21-26 (2006).

158. Guzman, C.A. et al. Vaccines against typhoid fever. Vaccine 24, 38043811 (2006).

159. Gil-Cruz, C. et al. The porin OmpD from nontyphoidal Salmonella is a key target for a protective $\mathrm{B} 1 \mathrm{~b}$ cell antibody response. Proc. Natl Acad. Sci. USA 106, 9803-9808 (2009). 